ARTIGOS / ARTICLES

DOI: $10.5433 / 1679-0383.2021 v 42 n 2 p 183$

\title{
Impeachment e remoção presidencial no Brasil: estudo qualitativo das condições de sucesso e fracasso
}

\section{Impeachment and presidential removal in Brazil: a qualitative study of the conditions for success and failure}

\author{
Francisco Gandolfi de Tulio ${ }^{1}$, Ivan Souza Vieira ${ }^{2}$
}

\section{Resumo}

\begin{abstract}
A partir dos pressupostos da Teoria dos Conjuntos (Set-Theoretic Methods), foi feito um estudo qualitativo e comparado (Qualitative Comparative Analysis - QCA) da remoção presidencial no Brasil, observando os governos de Fernando Collor de Mello, Fernando Henrique Cardoso, Luiz Inácio Lula da Silva e Dilma Rousseff. Discutindo a importância relativa de cada condição a partir da estratégia metodológica adotada, o artigo apresenta um modelo de condições necessárias, e em conjunto suficientes, para que a remoção presidencial ocorra no Brasil. Dentre elas, destaca-se o alinhamento do presidente da Câmara dos Deputados e as taxas de disciplina da coalizão, de sucesso e de dominância do Executivo no quadro de condições "institucionais" mais importantes; enquanto a baixa popularidade e o mau desempenho econômico da gestão foram as condições "não institucionais" mais importantes para que o mandato do chefe do Executivo seja interrompido.
\end{abstract}

Palavras-chave: Impeachment; Remoção presidencial; Brasil; Qualitative Comparative Analysis (QCA).

\begin{abstract}
Based on the "Set-Theoretic Methods" assumptions we conducted a Qualitative Comparative Analysis (QCA) of the presidential removal in Brazil, observing the administration of Fernando Collor de Mello, Fernando Henrique Cardoso, Luiz Inácio Lula da Silva and Dilma Rousseff. Discussing the relative importance of each condition based on the methodological strategy adopted the article presents a model of the necessary and together sufficient conditions for a presidential removal to take place in Brazil. These include the alignment of the President of the Chamber of Deputies and the coalition discipline of the administration, together with the success and dominance rates of the President in the Legislative as the most important "institutional" conditions. The low popularity of the President and the poor economic performance of the administration were found to be the most important "non-institutional" conditions for a presidential removal to take place in Brasil.
\end{abstract}

Keywords: Impeachment; Presidential removal; Brazil; Qualitative Comparative Analysis (QCA).

\footnotetext{
${ }^{1}$ Mestrado em Direito e Desenvolvimento pela Fundação Getúlio Vargas (FGV), São Paulo, São Paulo, Brasil. E-mail: franciscodetulio@hotmail.com

${ }^{2}$ Doutorando em Ciência Política pelo Centro de Investigación y Docencia Económicas (CIDE), Ciudad de México, México.E-mail: ivan.vieira@outlook.com.br
} 


\section{Introdução}

Desde a redemocratização o Brasil enfrentou dois processos de remoção presidencial com êxito. Fernando Collor de Mello, em dezembro de 1992, renunciou ao cargo de presidente meses após a abertura do processo de impeachment. Já Dilma Rousseff, à época em seu segundo mandato, teve o cargo cassado após julgamento pelo Senado Federal em agosto de 2016.

Apesar de o impeachment ser um fenômeno complexo e multifacetado, o objetivo deste artigo foi sistematizar as condições necessárias, e em conjunto suficientes, para que um presidente da República seja removido de seu cargo no Brasil. Para isso, foi feito um estudo qualitativo e comparado (Qualitative Comparative Analysis - QCA) do governo de Fernando Collor de Mello e das duas gestões de Fernando Henrique Cardoso (FHC), duas gestões de Luiz Inácio Lula da Silva e duas gestões de Dilma Rousseff.

A seleção das condições a serem testadas foi feita com base na literatura que trata do presidencialismo de coalizão e da democracia brasileira pós-1988, explorando as formas e os mecanismos institucionais dos quais o(a) presidente do Brasil dispõe para garantir um nível satisfatório de governabilidade, implementar a sua agenda política e se manter no cargo (FIGUEIREDO; LIMONGI, 1998; 2007; ABRANCHES, 2018; FREITAS, 2013; SANTOS, 2006). Procuramos dialogar, ainda, com a literatura que enfatiza as crises presidenciais na América Latina e os respectivos processos de renúncias e abandonos de cargo, impeachment e declaração de incapacidade (PÉREZ-LIÑÁN, 2007; 2014; LLANOS; MARSTEINTREDET, 2010).

Por fim, a partir da sistematização e do teste das condições que podem ocasionar um impeachment bem-sucedido, identificamos a importância relativa de cada uma dessas condições para que a remoção presidencial ocorra no Brasil.

\section{Fatores de estabilidade e instabilidade do sistema presidencialista}

A Constituição Federal de 1988 representou um importante marco na estrutura políticoinstitucional do Brasil. O texto constitucional alterou o equilíbrio de poderes que havia sido estabelecido no período democrático anterior (1946-1964), atribuindo fortes poderes legislativos e de agenda ao Executivo e à figura do presidente da República (FIGUEIREDO; LIMONGI, 2007, p. 148).

$\mathrm{O}$ arranjo institucional estabelecido pelos constituintes de 1988 foi alvo de crítica por setores da academia durante a década de $1990 . \mathrm{Na}$ perspectiva de Lamounier (1992), por exemplo, o modelo adotado levaria o País a uma "democracia consociativa", em que o regime presidencial combinado à fragmentação partidária e multiplicidade de contrapesos não ofereceria incentivos institucionais suficientes para a formação de uma base parlamentar capaz de garantir estabilidade e governabilidade.

No entanto, outro conjunto de análises se opôs à perspectiva de Lamounier (1992). Neste contexto de crítica surgiu o conceito de "presidencialismo de coalizão".

O termo, que aparece no ano de 1988 em artigo clássico de Sérgio Abranches (1988), descreve o modelo institucional típico da América do Sul: o presidente constrói base de apoio concedendo postos ministeriais a membros dos partidos com representação no Congresso, e estes, em troca, fornecem os votos necessários para aprovar sua agenda no Legislativo (SANTOS, 2006, p. 225).

Deste modo, os teóricos do presidencialismo de coalizão refutam a ideia de que a combinação institucional brasileira pós-1988 (de regime presidencialista majoritário e multipartidarismo com sistema de representação proporcional de lista aberta para a Câmara dos Deputados) provocou ingovernabilidade ao presidente. Conforme Santos (2006) 
demonstra empiricamente, os poderes institucionais conferidos ao presidente da República criaram mecanismos capazes do poder Executivo se empenhar na formação de uma base parlamentar majoritária.

Nesse sentido, a Constituição Federal de 1988 produziu um Executivo "forte e bem equipado" e que, combinado com a elevada disciplina parlamentar verificada no período, teria sido responsável pela formação de governos estáveis e com alta capacidade de aprovar a sua agenda no Parlamento.

Dentre as variáveis que alguns dos principais teóricos do presidencialismo de coalizão analisam para a verificação do seu modelo - como Figueiredo e Limongi (1988; 2007), Abranches (2018) e Freitas (2013) - estão: a coalizão presidencial na Câmara dos Deputados, observando a sua formação, tamanho, estabilidade e a fragmentação do sistema partidário; e as taxas de sucesso e de dominância do Executivo, i.e., a porcentagem de projetos do Executivo apresentados e sancionados durante o próprio governo e a porcentagem de projetos do Executivo aprovados em relação ao total de propostas aprovadas, respectivamente.

Já os estudos sobre remoção presidencial destacam os períodos de instabilidade do sistema presidencialista. Enquanto os teóricos do presidencialismo de coalizão comumente ilustram os fatores e as causas que garantem ao presidente bons índices de governabilidade no Brasil, autores como Pérez-Liñán (2007; 2014) e Llanos e Marsteintredet (2010) se inclinam para os casos latino-americanos em que o(a) chefe do poder executivo enfrentou obstáculos para se manter no cargo ${ }^{3}$.

De acordo com a análise conduzida por Llanos e Marsteintredet (2010), a fraqueza presidencial (relacionada a casos de crise econômica e de apoio parlamentar minoritário) associada a contextos de revolta política do Congresso e de realização de grandes protestos populares são alguns dos fatores centrais para explicar porque a remoção presidencial tem sido frequente em países latinoamericanos ao longo das últimas décadas. De modo análogo, Pérez-Liñán $(2007 ; 2014)$ também ressalta a importância dos escândalos políticos e de revoltas populares como fatores relevantes para se compreender como cenários de instabilidade são construídos em sistemas presidencialistas. De forma complementar, o autor considera que a formação de um "escudo legislativo", que proteja o presidente de possíveis investidas dos parlamentares, é um fator central para explicar a ocorrência de situações de crise e instabilidade.

Levando em consideração os fatores de estabilidade e instabilidade apontados por ambas vertentes da literatura, a seguir indicamos as variáveis que utilizamos para a construção da nossa análise comparativa entre os casos brasileiros de manutenção e destituição do cargo de presidente da República.

Partindo da divisão proposta por teóricos da remoção presidencial, optamos por segmentar as variáveis em dois diferentes grupos: o primeiro, de fatores institucionais, refere-se estritamente ao jogo político e à relação entre o poder Executivo e o poder Legislativo no caso brasileiro; já o segundo grupo abarca os fatores não institucionais, que dizem respeito a dinâmicas sociais e econômicas relevantes para que o presidente da República mantenha o apoio da população e do Congresso Nacional. Os critérios adotados para a calibração de cada um dos fatores institucionais e não institucionais, seguindo a metodologia do QCA (Qualitative Comparative Analysis), são apresentados no Quadro 1.

\footnotetext{
${ }^{3}$ Segundo Llanos e Marsteintredet (2010, p. 4), entre as décadas de 1980 e 2000 existiram ao menos catorze casos de ruptura presidencial na América Latina - em países como Argentina, Brasil, Bolívia, República Dominicana, Equador, Guatemala, Paraguai, Peru e Venezuela.
} 
Quadro 1 - Variáveis selecionadas e calibração das condições.

\begin{tabular}{|c|c|c|c|}
\hline Variáveis & Descrição & Calibração & Fontes / referências \\
\hline \multirow{2}{*}{$\begin{array}{l}\text { Número de cadeiras do } \\
\text { partido do(a) presidente na } \\
\text { Câmara dos Deputados }(\%)\end{array}$} & \multirow{2}{*}{$\begin{array}{l}\text { Qual a representatividade } \\
\text { do partido do(a) presidente } \\
\text { na Câmara dos Deputados. }\end{array}$} & $\begin{array}{l}\text { 1: se ao longo do mandato o partido do presidente não teve o número } \\
\text { de cadeiras necessárias na Câmara dos Deputados para formar } \\
\text { o "escudo legislativo" (171 de } 513 \text {, ou } 33,3 \%) \text {. }\end{array}$ & \multirow{2}{*}{$\begin{array}{l}\text { Pérez-Liñán } \\
\text { (2007 e 2014) }\end{array}$} \\
\hline & & $\begin{array}{l}\text { 0: se ao longo do mandato o partido do presidente teve o número } \\
\text { de cadeiras necessárias na Câmara dos Deputados para formar } \\
\text { o "escudo legislativo" (171 de 513, ou 33,3\%). }\end{array}$ & \\
\hline \multirow{2}{*}{$\begin{array}{l}\text { Número de cadeiras } \\
\text { da coalizão presidencial } \\
\text { na Câmara dos Deputados } \\
\text { (início mandato/ } \\
\text { fim mandato) }(\%)\end{array}$} & \multirow{2}{*}{$\begin{array}{l}\text { Qual a representatividade } \\
\text { da coalizão de partidos } \\
\text { aliados ao(a) presidente } \\
\text { na Câmara dos Deputados. }\end{array}$} & $\begin{array}{l}\text { 1: se ao longo do mandato a coalizão do presidente na Câmara dos } \\
\text { Deputados não teve o número de cadeiras necessárias para formar } \\
\text { o "escudo legislativo" (171 de } 513 \text {, ou } 33,3 \%) \text {. }\end{array}$ & \multirow{2}{*}{$\begin{array}{l}\text { Pérez-Liñán } \\
\text { (2007 e 2014) }\end{array}$} \\
\hline & & $\begin{array}{l}\text { 0: se ao longo do mandato a coalizão do presidente na Câmara } \\
\text { dos Deputados teve o número de cadeiras necessárias para formar } \\
\text { o "escudo legislativo" ( } 171 \text { de } 513 \text {, ou } 33,3 \%) \text {. }\end{array}$ & \\
\hline \multirow{2}{*}{$\begin{array}{l}\text { Taxa de disciplina da } \\
\text { coalizão presidencial }(\%)\end{array}$} & \multirow{2}{*}{$\begin{array}{l}\text { De que forma a base de apoio } \\
\text { parlamentar do presidente vota os } \\
\text { projetos de lei, medidas provisórias } \\
\text { e emendas à Constituição Federal. }\end{array}$} & $\begin{array}{l}\text { 1: se a taxa de disciplina da coalizão do presidente é inferior à média } \\
\text { observada para todos os governos do período }(<82,67) \text {. }\end{array}$ & \multirow{2}{*}{$\begin{array}{l}\text { Figueiredo e Limongi } \\
\qquad(2007)\end{array}$} \\
\hline & & $\begin{array}{l}\text { 0: se a taxa de disciplina da coalizão do presidente é igual ou superior } \\
\text { à média observada para todos os governos do período }(=\text { ou }>82,67) \text {. }\end{array}$ & \\
\hline \multirow[t]{2}{*}{ Fragmentação partidária } & \multirow{2}{*}{$\begin{array}{l}\text { Nível de fragmentação do sistema } \\
\text { partidário de acordo com as legendas } \\
\text { que o compõem. }\end{array}$} & $\begin{array}{l}\text { 1: se o índice de fragmentação partidária é igual ou superior a } 5 \\
(=\text { ou }>5)\end{array}$ & \multirow{2}{*}{$\begin{array}{l}\text { Gallagher e Mitchell } \\
\qquad(2019)\end{array}$} \\
\hline & & 0: se o índice de fragmentação partidária é menor que $5(<5)$. & \\
\hline \multirow{2}{*}{$\begin{array}{l}\text { Presidente da Câmara } \\
\text { dos Deputados }\end{array}$} & \multirow{2}{*}{$\begin{array}{l}\text { Qual o partido do presidente da } \\
\text { Câmara dos Deputados e qual a sua } \\
\text { fidelidade em relação à orientação } \\
\text { partidária. }\end{array}$} & $\begin{array}{l}\text { 1: se o presidente da Câmara dos Deputados é da oposição ou da situação } \\
\text { E não fiel à orientação do seu partido. }\end{array}$ & \\
\hline & & $\begin{array}{l}\text { 0: se o presidente da Câmara dos Deputados é da situação E fiel } \\
\text { à orientação do seu partido. }\end{array}$ & \\
\hline \multirow{2}{*}{$\begin{array}{l}\text { Taxa de sucesso } \\
\text { do Executivo }\end{array}$} & \multirow{2}{*}{$\begin{array}{l}\text { Qual a porcentagem de projetos } \\
\text { do Executivo apresentados e } \\
\text { sancionados durante o próprio } \\
\text { governo. }\end{array}$} & $\begin{array}{l}\text { 1: se a taxa de sucesso do Executivo é inferior à média observada } \\
\text { para todos os governos analisados }(<66,55) \text {. }\end{array}$ & \multirow{2}{*}{$\begin{array}{l}\text { Figueiredo e Limongi } \\
\qquad(2007)\end{array}$} \\
\hline & & $\begin{array}{l}\text { 0: se a taxa de sucesso do Executivo é igual ou superior à média } \\
\text { observada para todos os governos analisados }(=\text { ou }>66,55) .\end{array}$ & \\
\hline
\end{tabular}




\section{Continuação}

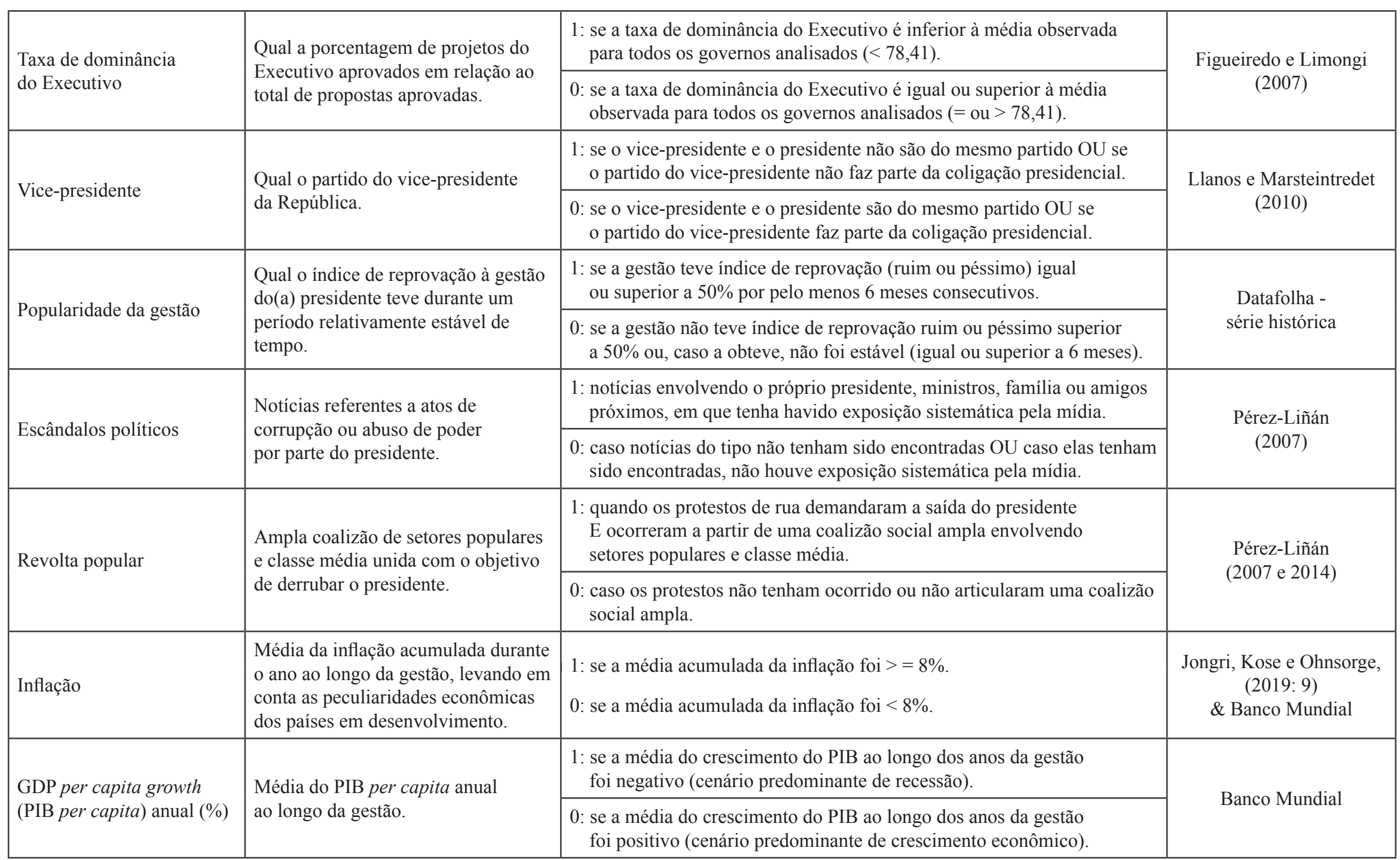

Legenda: GDP: Gross Domestic Product; PIB: Produto Interno Bruto.

Fonte: os autores. 


\section{Variáveis institucionais}

Número de cadeiras do partido e da coalizão do(a) presidente na Câmara dos Deputados e taxa de disciplina da coalizão presidencial

Em um sistema presidencialista e multipartidário como o brasileiro, o relacionamento do chefe do Executivo com os parlamentares que compõem a sua base é essencial para que o presidente tenha condições de implementar a sua agenda e, nos casos extremos, garantir o mínimo de apoio necessário para se manter no cargo. Considerandose que desde 1988 nenhum presidente democraticamente eleito teve com o seu partido a maioria (ou ao menos um terço) das cadeiras na Câmara dos Deputados (Quadro 2), a necessidade de se construir uma coalizão ampla e constante se torna cada vez mais relevante para a manutenção de itens satisfatórios de estabilidade e governabilidade.

Figueiredo e Limongi (1998; 2007) destacam que no período democrático recente todos os presidentes brasileiros eleitos (exceto Fernando Collor de Mello) formaram uma base parlamentar majoritária durante o mandato, com índices médios elevados de disciplina partidária (Quadro 2). Entre 1988 e 2014, contudo, verificamos que todos os chefes do poder Executivo foram capazes de formar um “escudo legislativo" (PÉREZ-LIÑÁN, 2007; 2014) - número necessário de cadeiras na Câmara dos Deputados que permite vetar um eventual pedido de impeachment (171 parlamentares, ou 33,3\%).

Assim, olhar para a coalizão presidencial no Congresso Nacional e como esta se comportou ao longo do mandato se mostra relevante para a compreensão não só da força, mas também da fraqueza da autoridade executiva perante o Parlamento.

\section{Fragmentação do sistema partidário}

O sistema partidário brasileiro é apontado como um dos mais fragmentados do mundo (KINZO, 2004). O elevado número efetivo de partidos, combinado ao sistema de eleição majoritária para o Executivo, fornece incentivos para a formação de alianças e coligações, na medida em que a governabilidade só se torna viável por meio da união entre partidos (KINZO, 2004). No entanto, argumentase que a fragmentação intensa também implica em maiores níveis de complexidade de articulação entre Executivo e Legislativo, o que impõe maiores desafios à atuação do presidente (PEREIRA, 2017).

Neste trabalho medimos a fragmentação partidária na Câmara dos Deputados por meio do índice elaborado por Laakso e Taagepera (1979). Segundo este indicador, países com o grau superior a 5 possuem um nível de fragmentação elevado.

\section{Taxa de sucesso e de dominância do Executivo}

A taxa de sucesso e a taxa de dominância do Executivo se referem, respectivamente, ao número de projetos do Executivo apresentados e sancionados durante o próprio governo e o número de projetos do Executivo aprovados em relação ao total de propostas aprovadas. De acordo com Figueiredo e Limongi (1998; 2007), no período democrático recente foram constatadas elevadas taxas de sucesso e dominância do Executivo, quando comparado ao período de 1946-1964. Os índices elevados de sucesso e dominância do Executivo implicam em um forte poder Legislativo e de agenda do presidente e em uma grande capacidade de alteração do status quo.

\section{Presidente da Câmara dos Deputados}

Do ponto de vista jurídico, um dos ritos mais importantes do processo de impeachment ocorre durante a tramitação do mesmo na Câmara dos Deputados. Apesar do julgamento se dar no Senado Federal, sob a supervisão do presidente do Supremo Tribunal Federal, o processo inicia-se na Câmara dos Deputados, quando o presidente da Casa, após a análise do mérito da denúncia, decide se a recebe ou não.

O presidente da Câmara dos Deputados, nesse sentido, ocupa posição estratégica dentro do rito processual do impeachment, pois se converte 
em um veto player relevante: se logo no início ele já opta pela rejeição da denúncia, o processo é arquivado e o presidente não terá que arcar com os custos de mobilizar a sua base de apoio para barrar o pedido em outros momentos de tramitação.

Do exposto, se depreende que um possível alinhamento do presidente da República com o presidente da Câmara é essencial para impedir a tramitação do processo logo em seu período inicial.

\section{Vice-presidente da República}

A literatura que trata da remoção presidencial também assinala o papel que a figura do vice-presidente pode desempenhar em momentos de crise presidencial, dado este ser o próximo na linha sucessória. Linz (1990) argumenta que a estabilidade do presidente pode ser colocada em risco caso o vice não seja do mesmo partido. Já Llanos e Marsteintredet (2010) sugerem que em momentos de crise o vice-presidente possui poucos incentivos para apoiar o chefe do Executivo, na medida em que a proximidade com o presidente pode fazer com que os dois sejam destituídos de seus cargos. Ainda, um distanciamento do vice em relação à crise pode aumentar as suas chances de assumir o novo governo, assim como pode contribuir para o aprofundamento da crise.

Quadro 2 - Variáveis institucionais e respectivos dados.

\begin{tabular}{|l|c|c|c|c|c|c|}
\hline Presidente & $\begin{array}{c}\text { Taxa de } \\
\text { disciplina da } \\
\text { coalizão } \\
\text { presidencial (\%) }\end{array}$ & $\begin{array}{c}\text { Índice de } \\
\text { fragmentação } \\
\text { partidária }\end{array}$ & $\begin{array}{c}\text { Presidente da } \\
\text { Câmara dos } \\
\text { Deputados } \\
\text { (partido) }\end{array}$ & $\begin{array}{c}\text { Taxa de } \\
\text { sucesso do } \\
\text { Executivo }\end{array}$ & $\begin{array}{c}\text { Taxa de } \\
\text { dominância do } \\
\text { Executivo }\end{array}$ & Vice-presidente \\
\hline Collor & 79,6 & 8,69 & PMDB & 61,11 & 74,55 & $\begin{array}{c}\text { Itamar Franco } \\
\text { (PRN/ } \\
\text { sem partido) }\end{array}$ \\
\hline FHC I & 85,9 & 8,16 & PFL-PMDB & 79,13 & 83,2 & $\begin{array}{c}\text { Marco Maciel } \\
\text { (PFL/DEM) }\end{array}$ \\
\hline FHC II & 90,9 & 7,14 & PMDB-PSDB & 73,59 & 80,19 & $\begin{array}{c}\text { Marco Maciel } \\
\text { (PFL/DEM) }\end{array}$ \\
\hline Lula I & 87,4 & 8,47 & PT-PP-PCdoB & 76,76 & 74,99 & $\begin{array}{c}\text { José Alencar } \\
\text { (PL/PRB) }\end{array}$ \\
\hline Lula II & 88,6 & 9,32 & PT-PMDB & 67,38 & 85,77 & $\begin{array}{c}\text { José Alencar } \\
\text { (PL/PRB) }\end{array}$ \\
\hline Dilma I & 76,9 & 10,36 & PT-PMDB & 61,81 & 80,06 & $\begin{array}{c}\text { Michel Temer } \\
\text { (PMDB) }\end{array}$ \\
\hline Dilma II & 69,4 & 13,22 & PMDB & 46,09 & 70,1 & $\begin{array}{c}\text { Michel Temer } \\
\text { (PMDB) }\end{array}$ \\
\hline
\end{tabular}

Legenda: Collor: Fernando Collor de Mello; FHC: Fernando Henrique Cardoso; Lula: Luiz Inácio Lula da Silva; Dilma: Dilma Rousseff.

Fonte: Banco de Dados Legislativos do Centro Brasileiro de Análise e Planejamento (CEBRAP, 2019); Câmara dos Deputados (2019); Figueiredo e Limongi (2007); Pereira (2017); Gallagher e Mitchell (2019); arquivos da Biblioteca da Presidência da República (2019).

\section{Variáveis não institucionais}

\section{Popularidade da gestão}

A popularidade da gestão deve ser considerada como um elemento central na análise de qualquer processo de remoção presidencial.
É razoável pressupor que a remoção de um presidente seja facilitada em casos de grande insatisfação popular com a sua gestão, pois os custos de manutenção no poder seriam significativamente maiores. Nesse sentido, parte da literatura aponta que presidentes populares enfrentariam menos dificuldades de construir e manter coalizões políticas, 
reduzindo seus custos por constranger os membros do parlamento perante os eleitores (BERTHOLINI; PEREIRA, 2017, p. 536).

Para que a percepção do eleitorado sobre a gestão presidencial se converta em impopularidade, adotamos o parâmetro de $50 \%$ de rejeição (ruim ou péssimo) por um período relativamente estável de tempo - pelo menos 6 meses - a partir da série histórica do instituto Datafolha. Com isso, o objetivo foi testar em quais casos a rejeição esteve presente para, pelo menos, metade do eleitorado e se esse cenário de alta desaprovação foi contornado de forma bem-sucedida ou não por algum presidente até o fim de seu mandato.

\section{Revoltas populares}

Para que uma mobilização popular ameace ou represente algum risco ao chefe do Executivo, é preciso estarmos diante de uma ampla coalizão envolvendo setores populares e classe média unida com o objetivo de derrubar o presidente (PÉREZLIÑÁN, 2007; 2014). Nesse sentido, movimentos pro-impeachment teriam impacto reduzido ao refletir interesses limitados ou quando falham em incorporar importantes setores sociais (PÉREZLIÑÁN, 2007, p. 124).

O movimento "Caras Pintadas" em 1992 contra o governo Collor 4 , a "Marcha dos 100 mil" no governo $\mathrm{FHC}^{5}$ e as manifestações em 2015 e $2016^{6}$ a favor da saída de Dilma Rousseff foram mobilizações que tiveram como pauta o pedido de afastamento do chefe do Executivo e envolveram ampla coalizão com diferentes setores sociais no período pós-redemocratização. Apesar de não termos pesquisas que deem conta da composição social desses movimentos, consideramos que eles se enquadram como "revoltas populares", dado a heterogeneidade dos setores envolvidos e a proporção dessas manifestações.

\section{Escândalos políticos}

Para Peréz-Liñan (2007) escândalos políticos são atos de abuso de poder ou corrupção, sendo este último definido como notícias envolvendo o próprio presidente, ministros, família ou amigos próximos, em que tenha havido exposição sistemática pela mídia. No caso brasileiro, escândalos de corrupção, quando ocorrem e afetam o núcleo duro do governo, geralmente implicam em um desgaste da coalizão presidencial (ABRANCHES, 2018, cap. 3).

\section{Fatores econômicos}

No Brasil, em contexto de crise econômica a popularidade do presidente cai, assim como a sua força de atração em relação à sua base política; com isso, temos um cenário de fortalecimento da oposição e a liderança presidencial é questionada, sendo nas fases mais maduras desse ciclo que surge o risco de impeachment (ABRANCHES, 2018, p. 350-356). Duas condições econômicas nos parecem de especial importância para serem verificadas em um caso de impeachment: o crescimento anual do Produto Interno Bruto (PIB) per capita e a inflação do período (KIM, 2014). Juntos, esses fatores podem ser particularmente danosos ao presidente.

De acordo com a literatura, há uma associação negativa entre taxa de inflação e crescimento econômico que vem sendo estimada abaixo de $10 \%$ para os países desenvolvidos e em torno de

${ }^{4}$ A articulação envolveu partidos políticos, movimento estudantil e entidades da sociedade civil. Para detalhes ver Mische (2008, cap. 5) e Sallum Jr. (2016, p. 193-200).

5 A Marcha dos 100 mil no governo FHC tinha como uma de suas pautas o pedido de impeachment/renúncia do presidente e contou com a participação de diversos partidos de oposição, movimentos sociais, assim como de setores da igreja (MADUEÑO; GONDIM; ZORZAN, 1999; ATO..., 1999; ECONOMIST..., 1999).

${ }^{6}$ Em março de 2016, mais de 3 milhões de manifestantes foram às ruas em diferentes estados da federação (MANIFESTANTES..., 2016). Ao analisar as manifestações em São Paulo, Alonso (2017, p. 55) destaca que "empresariado, associações patronais e setores organizados de classe média e alta deram suporte logístico". 
$20 \%$ para as economias emergentes (JONGRIM, KOSE E OHNSORGE, 2019, p. 9). Estudo recente apontou que, para países emergentes com certo grau de qualidade institucional, no qual o Brasil foi inserido, a taxa de inflação limite para que haja impacto negativo no crescimento econômico foi estimada em torno de 7,9\% (IBARRA; TRUPKIN, 2011). Assim, trabalharemos com a média do PIB per capita anual ao longo da gestão e com o limite de $8 \%$ da taxa de inflação (consumer prices index), ambos retirados da série histórica do Banco Mundial.

Quadro 3 - Variáveis não institucionais e respectivos dados.

\begin{tabular}{|c|c|c|c|c|c|}
\hline Presidente & $\begin{array}{l}\text { Rejeição da gestão } \\
\text { presidencial } \\
\text { (ruim ou péssimo) }\end{array}$ & $\begin{array}{l}\text { Escândalo } \\
\text { político } \\
\text { (exemplos) }\end{array}$ & $\begin{array}{l}\text { Revoltas } \\
\text { populares }\end{array}$ & $\begin{array}{c}\text { Média } \\
\text { PIB per capita } \\
(\%)\end{array}$ & $\begin{array}{c}\text { Média da inflação } \\
\text { acumulada } \\
\text { durante a gestão } \\
(\%)\end{array}$ \\
\hline \multirow[t]{2}{*}{ Collor } & $\begin{array}{l}48 \%-68 \% \\
\text { em } 6 \text { meses }\end{array}$ & $\begin{array}{l}\text { Denúncias contra } \\
\text { os ministros } \\
\text { do Trabalho } \\
\text { e da Saúde }\end{array}$ & \multirow{2}{*}{$\begin{array}{c}\text { Movimentos } \\
\text { pro-impeachment } \\
1992\end{array}$} & \multirow[t]{2}{*}{$-2,4$} & \multirow[t]{2}{*}{1443} \\
\hline & $\begin{array}{l}(01 / 03 / 92- \\
01 / 09 / 92)\end{array}$ & $\begin{array}{l}\text { Esquema } \\
\text { PC Farias }\end{array}$ & & & \\
\hline FHC I & $\begin{array}{l}\text { 25\% máximo } \\
(01 / 06 / 96)\end{array}$ & Caso Sivam & - & 0,98 & 23 \\
\hline \multirow[t]{2}{*}{ FHC II } & $\begin{array}{c}\text { Flutuação } \\
\text { 44\%-56\%-46\% } \\
\text { em } 5 \text { meses }\end{array}$ & Caso Sudam & \multirow{2}{*}{$\begin{array}{c}\text { Marcha } \\
\text { dos } 100 \text { mil }\end{array}$} & \multirow[t]{2}{*}{0,87} & \multirow[t]{2}{*}{6,72} \\
\hline & $\begin{array}{l}(01 / 06 / 99- \\
01 / 12 / 99)\end{array}$ & Painel do Senado & & & \\
\hline \multirow{2}{*}{ Lula I } & $29 \%$ máximo & Mensalinho & \multirow{2}{*}{ - } & \multirow{2}{*}{2,35} & \multirow{2}{*}{8,1} \\
\hline & $(14 / 12 / 05)$ & Mensalão & & & \\
\hline \multirow{2}{*}{ Lula II } & $15 \%$ máximo & \multirow{2}{*}{ Mensalão } & \multirow{2}{*}{ - } & \multirow{2}{*}{3,59} & \multirow{2}{*}{4,82} \\
\hline & $(02 / 08 / 07)$ & & & & \\
\hline \multirow[t]{2}{*}{ Dilma I } & 29\% máximo & $\begin{array}{l}\text { Caso Petrobras e } \\
\text { outros escândalos } \\
\text { ministeriais }\end{array}$ & \multirow[t]{2}{*}{ - } & \multirow[t]{2}{*}{1,4} & \multirow[t]{2}{*}{6,14} \\
\hline & $(16 / 07 / 14)$ & Lava Jato & & & \\
\hline \multirow{3}{*}{ Dilma II } & $\begin{array}{c}\text { Acima de } 60 \% \\
\text { por } 1 \text { ano e } 4 \text { meses }\end{array}$ & Caso Petrobras & \multirow{3}{*}{$\begin{array}{l}\text { Pro-impeachment } \\
2015 \text { e } 2016\end{array}$} & \multirow{3}{*}{-4} & \multirow{3}{*}{8,88} \\
\hline & $\begin{array}{c}(14 / 04 / 15- \\
08 / 04 / 16)\end{array}$ & Lava Jato & & & \\
\hline & & Pedaladas Fiscais & & & \\
\hline
\end{tabular}

Legenda: Collor: Fernando Collor de Mello; FHC: Fernando Henrique Cardoso; Lula: Luiz Inácio Lula da Silva; Dilma: Dilma Rousseff. PIB: Produto Interno Bruto.

Fonte: os autores, a partir de indicadores do Banco Mundial (PIB e inflação). Popularidade via Datafolha. Escândalos políticos mapeados em Azevedo (2010); Chaia e Teixeira (2001); Araújo, Costa e Fittipaldi (2016). Veículos de comunicação consultados: Folha de S.Paulo, O Estado de S. Paulo (Estadão), Época, O Globo e Carta Maior. 


\section{Metodologia}

O impeachment é um fenômeno complexo e multifacetado. Justamente por isso seu estudo traz algumas peculiaridades metodológicas:

Eles estão situados ao final de uma cadeia de eventos, o que torna extremamente difícil sopesar quais fatores são decisivos para a remoção presidencial. Crises econômicas, fim de coalizões, crises governamentais internas, escândalos, impasses políticos e protestos sociais muitas vezes precedem conjuntamente a saída antecipada de um presidente. Assim, tomando emprestado de Ragin (1987: 27), os colapsos presidenciais parecem ser causados pelo efeito combinado de um conjunto ou conjunção de fatores causais que se cruzam em um determinado momento no tempo, criando uma "tempestade perfeita" que atinge o presidente (LLANOS; MARSTEINTREDET, 2010, p. 213, tradução livre).

Neste artigo, apresentamos quais condições integram a "tempestade perfeita" brasileira, sem nos preocuparmos com a ordem da cadeia causal de eventos (ex.: escândalo político $->$ [acarreta] baixa na popularidade do presidente $->$ [acarreta] revoltas populares), o que ocupa grande parte da literatura de política comparada sobre remoção presidencial.

Nos limitaremos a apresentar quais condições estiveram presentes nos dois casos de impeachment bem-sucedidos no Brasil, identificando a importância relativa de cada condição para o resultado final, a partir da comparação com os casos em que a remoção não ocorreu (FHC I-II, Lula I-II, Dilma I).

Para a realização deste estudo qualitativo e comparado utilizamos o Qualitative Comparative Analysis (QCA) com o objetivo de formular as condições necessárias mínimas para que certo resultado aconteça, considerando que diferentes configurações de condições podem conduzir a um mesmo resultado. Nas chamadas "set theories" (Teoria dos Conjuntos), trabalha-se com os conceitos de condições necessárias e suficientes.
Nos termos de Blatter e Haverland (2012, p. 92-93, tradução livre):

- Um fator causal (X) é uma condição necessária se o resultado $(\mathrm{Y})$ ocorre apenas quando $\mathrm{X}$ está presente. No entanto, Y nem sempre precisa ocorrer se $\mathrm{X}$ existir. Em outras palavras, Y não é possível sem $\mathrm{X}$, mas $\mathrm{X}$, quando presente, não necessariamente leva a $\mathrm{Y}$.

- Um fator causal (X) é uma condição suficiente se o resultado (Y) sempre ocorre quando $X$ existe. No entanto, $Y$ pode também ocorrer quando $\mathrm{X}$ não existir. Em outras palavras, $\mathrm{X}$ sempre leva a Y, mas Y é também possível sem X.

Para os fins desta pesquisa, foi utilizada a abordagem "two-step", relativa às condições que podem ser divididas em fatores "remotos" e "próximos" (SCHNEIDER; WAGEMANN, 2012). Fatores remotos são aqueles cuja origem geralmente é distante temporalmente do resultado da análise. São situações estáveis, difíceis de serem modificadas pelos atores e, portanto, muitas vezes tratados como exógenos ou estruturais. Já os fatores próximos são aqueles cuja origem não é tão distante quanto dos fatores remotos, sendo mais facilmente modificáveis pela ação humana (SCHNEIDER; WAGEMANN, 2012, p. 253).

No presente artigo, fatores remotos foram denominados de "condições não institucionais", pois dizem respeito à dinâmica econômica e social. As condições institucionais, por sua vez, são as regras associadas ao jogo político, que moldam e permitem uma ação direta e calculada dos atores.

Logo, as condições elencadas na seção anterior foram marcadas como "presente" (1) ou "não presente" (0) e colocadas em uma "tabela verdade" (truth table), conforme os critérios de calibragem descritos no decorrer do estudo, e para processar a comparação utilizamos o software Tosmana.

\section{Análise dos dados}

A partir do levantamento de dados sobre as variáveis institucionais obtivemos o resultado que se observa no Quadro 4: 
Quadro 4 - Truth table: variáveis institucionais.

\begin{tabular}{|l|c|c|c|c|}
\hline \multirow{2}{*}{\multicolumn{1}{|c|}{ Variáveis institucionais }} & \multicolumn{4}{|c|}{ Presidente } \\
\cline { 2 - 5 } & FHC I, FHC II, Lula II & Lula I & Dilma I & Collor, Dilma II \\
\hline $\begin{array}{l}\text { Cadeiras do partido do(a) presidente } \\
\text { na Câmara dos Deputados }\end{array}$ & 1 & 1 & 1 & 1 \\
\hline $\begin{array}{l}\text { Cadeiras da coalizão presidencial } \\
\text { na Câmara dos Deputados }\end{array}$ & 0 & 0 & 0 & 0 \\
\hline Taxa de disciplina da coalizão & 0 & 0 & 1 & 1 \\
\hline Fragmentação partidária & 1 & 1 & 1 & 1 \\
\hline Presidente da Câmara dos Deputados & 0 & 0 & 0 & 1 \\
\hline Taxa de sucesso do Executivo & 0 & 0 & 1 & 1 \\
\hline Taxa de dominância do Executivo & 0 & 1 & 0 & 1 \\
\hline Vice-presidente & 0 & 0 & 0 & 0 \\
\hline Resultado & $\mathbf{0}$ & $\mathbf{0}$ & $\mathbf{0}$ & $\mathbf{1}$ \\
\hline
\end{tabular}

Legenda: FHC: Fernando Henrique Cardoso; Lula: Luiz Inácio Lula da Silva; Dilma: Dilma Rousseff; Collor: Fernando Collor de Mello.

Fonte: os autores.

De acordo com o resultado obtido pelo cruzamento dos fatores institucionais, observamos que a efetivação do processo de impeachment ocorre quando: (i) o número de cadeiras do partido do presidente for menor que $1 / 3$, apesar da coalizão formar o escudo legislativo; E (ii) a taxa de disciplina da coalizão presidencial, (iii) a taxa de sucesso do Executivo E a (iv) taxa de dominância do Executivo forem inferiores à média observada para todos os governos do período; E o (v) presidente da Câmara dos Deputados ser da oposição OU da situação e não fiel à orientação do seu próprio partido $\mathrm{E}$ (vi) o vice-presidente for do mesmo partido do presidente ou pertencer à sua coalizão.

Vale destacar que todas as oito condições que compõem o grupo dos fatores institucionais apresentaram o mesmo comportamento nos casos em que o impeachment ocorreu - ou seja, Collor e Dilma II possuem a mesma configuração de condições. Dentre o conjunto analisado, somente duas condições - o número cadeiras da coalizão presidencial na Câmara dos Deputados e o partido ou coligação partidária do vice-presidente - não estiveram presentes.

A análise comparativa do QCA nos permitiu inferir as condições que são mais ou menos importantes para a ocorrência do impeachment. Goertz (2006, p. 90-92) traz uma distinção baseada na frequência da presença de determinada condição para determinar sua importância enquanto causa necessária: uma condição necessária é mais importante quanto mais próxima a sua frequência se aproximar do resultado Y.

Deste modo, considerando a frequência pela qual as condições institucionais apareceram no modelo, temos a seguinte ordem de importância: presidente da Câmara dos Deputados da oposição ou da situação e não alinhado à orientação do seu partido $>^{7}$ taxas de disciplina da coalizão, de sucesso e de dominância inferiores à média de todos os governos $>$ número de cadeiras na Câmara menor que $1 / 3$ para o partido do presidente e maior que

\footnotetext{
${ }^{7}$ Leia-se "mais importante que".
} 
1/3 para a coalizão, índice de fragmentação partidária elevado $(>5)$ e vice-presidente filiado ao partido do presidente ou ao menos que integre a coalizão governista.

Sobre a condição institucional mais importante de acordo com o modelo, destacamos que os governos de FHC, Lula e Dilma I contaram com a presença de um presidente da Câmara dos Deputados que, se não fosse do partido do(a) presidente da República, ao menos fazia parte da coalizão presidencial e era fiel à sua sigla. No caso de Collor, contudo, o partido do presidente da Câmara, Ibsen Pinheiro (PMDB) não integrava formalmente a coalizão do governo; Pinheiro, portanto, decidiu prosseguir com o pedido de abertura de impeachment. No segundo mandato de Dilma, apesar de Eduardo Cunha ser membro de um partido que inicialmente compunha a base governista (PMDB), este rompeu com o governo e aceitou, em dezembro de 2015, a abertura do pedido de impeachment.

$\mathrm{O}$ aceite dos pedidos de abertura de processo de impeachment por Ibsen Pinheiro e Eduardo
Cunha representam uma quebra no padrão comumente adotado por presidentes da Câmara dos Deputados no período pós-1988. Apesar de terem sido protocolados 162 pedidos de impeachment entre o início do governo Collor e o fim do governo Dilma ${ }^{8}$, apenas dois foram aceitos pela presidência da Câmara e obtiveram êxito na demanda a qual se propunham.

No prosseguimento da ordem de importância das condições institucionais, temos as taxas de disciplina da coalizão, de sucesso e de dominância, para então seguirmos com o número de cadeiras na Câmara dos Deputados e o índice de fragmentação partidária. Ainda que estas condições, em nosso modelo, tenham sido separadas em dois níveis distintos de importância, a abordagem comumente efetuada na literatura busca relacionar estes fatores para compreender a dinâmica do presidencialismo brasileiro no período democrático recente. Nesse sentido, para efeitos de compreender o comportamento destas condições para os casos de remoção presidencial, assumimos postura semelhante.

Gráfico 1 - Número de cadeiras da coalizão presidencial na Câmara dos Deputados (\%).

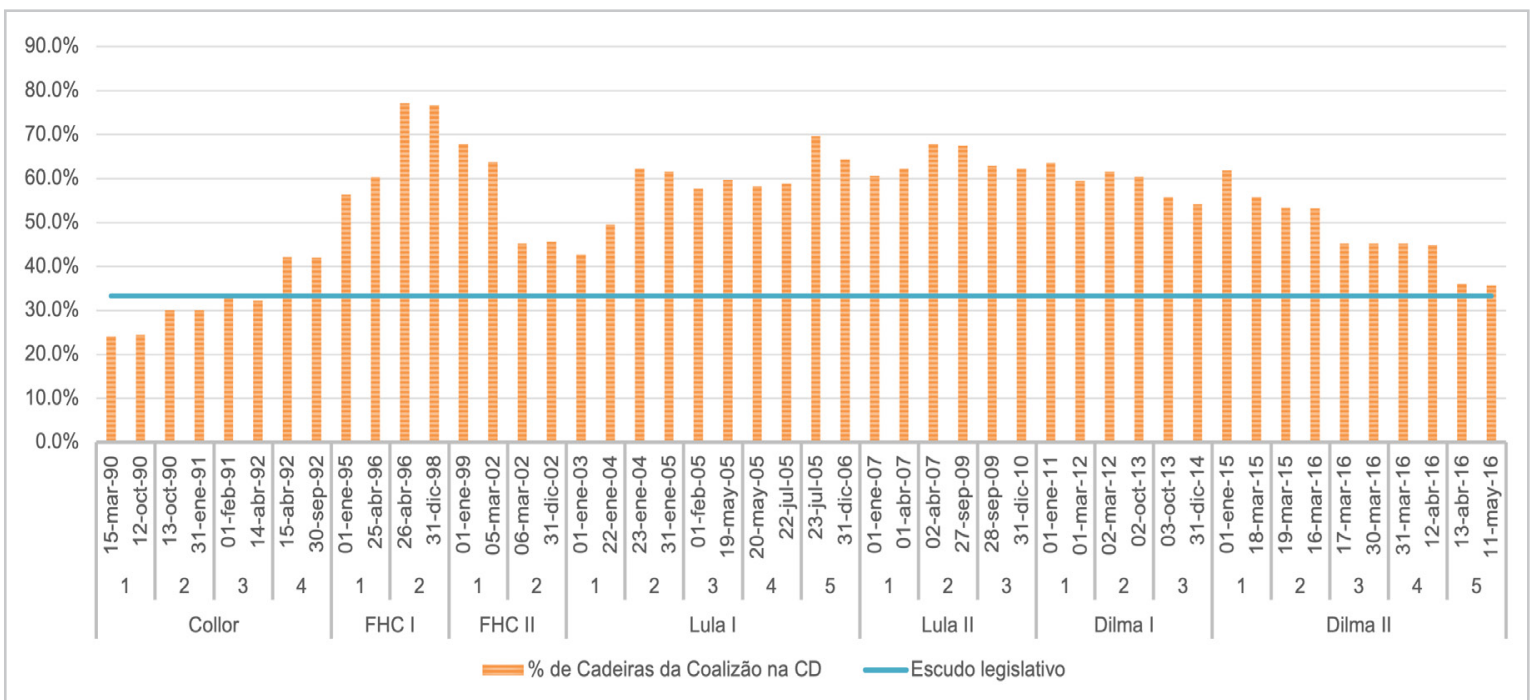

Legenda: Collor: Fernando Collor de Mello; FHC: Fernando Henrique Cardoso; Lula: Luiz Inácio Lula da Silva; Dilma: Dilma Rousseff.

Fonte: os autores, a partir do Banco de Dados Legislativos do Centro Brasileiro de Análise e Planejamento (CEBRAP, 2019).

\footnotetext{
${ }^{8}$ Foram 29 pedidos para Fernando Collor de Mello (com um aceito), 4 para Itamar Franco, 24 para Fernando Henrique Cardoso, 37 para Luiz Inácio Lula da Silva e 68 para Dilma Rousseff (com um aceito) (PRADO, 2016).
} 
A partir do Gráfico 1, notamos que no momento em que a Câmara dos Deputados aprovou o prosseguimento dos dois processos de impeachment do período democrático recente (em setembro de 1992 para Fernando Collor de Mello e maio de 2016 para Dilma Rousseff), ambos os presidentes detinham pouco mais de 1/3 de apoio parlamentar necessário para constituir o "escudo legislativo". Fernando Collor de Mello, apesar de ampliar a sua base durante os anos iniciais do mandato, conquistou até a véspera da votação na Câmara o apoio de 41,9\% dos deputados; no dia do pleito, entretanto, a coalizão se rompeu e parlamentares de partidos aliados votaram pela admissibilidade do processo (apenas 7,55\% da Casa votaram a favor do presidente). Dilma Rousseff, por sua vez, perdeu apoio político ao longo de seu segundo mandato: a coalizão da petista na Câmara dos Deputados caiu 26,1\% entre janeiro de 2015 e maio de 2016 (de 61,8\% para 35,7\%); no dia da votação, ainda, apenas dois partidos da base aliada votaram integralmente contra o afastamento da presidente (PT e PCdoB) (ALESSI, 2016).

Os dados acima corroboram a ideia de que o impeachment ocorre nos casos em que o governo dispõe de menor capacidade de articulação com o Congresso Nacional. A fragmentação partidária também foi elevada durante o período e nenhum partido do presidente conseguiu por si só eleger 1/3 de deputados para a Câmara; não obstante estas condições estarem presentes em todos os governos do período, em Collor e Dilma II foram onde verificamos maiores dificuldades na manutenção de uma coalizão estável e majoritária na Câmara dos Deputados, assim como as menores taxas de sucesso, de dominância e de disciplina da coalizão presidencial verificadas no período.

Por fim, sobre o vice-presidente, fazemos uma consideração que julgamos relevante. Apesar de esta condição assumir uma importância relativa menor no modelo dado a sua frequência, entendemos que em contextos de fragilidade política, analisar o comportamento do vice-presidente da República perante o cenário de instabilidade é um indicativo importante para averiguar as oportunidades do presidente se manter no cargo ou ser removido.

Num contexto de presidencialismo e de fragmentação partidária, em que o chefe do poder Executivo federal não dispõe da maioria nas casas legislativas e necessita de apoio parlamentar de outros partidos para implementar a sua agenda, é esperado que existam discordâncias de algum nível entre o presidente e o segundo na linha sucessória, visto que a escolha do vice-presidente não se baseia apenas na proximidade deste com o presidente ou o seu partido, mas na capacidade do vice-presidente atrair votos da população e/ou permitir a composição de uma base governista mais ampla no Congresso após as eleições. Dado estas circunstâncias, entre os anos de 1990 e 2016 nenhum presidente e vice-presidente foram do mesmo partido (com exceção de Fernando Collor de Mello e Itamar Franco, até o momento em que o último se desvinculou do PRN [Partido da Reconstrução Nacional]).

Parece-nos, portanto, que a estabilidade do mandato do presidente não é colocada em risco apenas nos casos em que estes (presidente e vicepresidente) não são do mesmo partido ou coalizão, como indica Linz (1990). Apesar do pertencimento à mesma base ser importante, é necessário verificar como o relacionamento entre os dois maiores chefes do Executivo se desenvolve em contextos de crise intensa. Nos casos de Collor e Dilma II, o resultado final, como sugerem os autores Llanos e Marsteintredet (2010), foi o surgimento do vicepresidente como uma alternativa para a superação da crise política.

A seguir, após cruzar os dados do Quadro 5 (truth table/tabela verdade) no software Tosmana, chegamos ao seguinte conjunto de variáveis não institucionais que devem estar presentes para que o impeachment ocorra: 
Quadro 5 - Truth table: variáveis não institucionais.

\begin{tabular}{|l|c|c|c|c|}
\hline \multirow{2}{*}{ Variáveis não institucionais } & \multicolumn{4}{|c|}{ Presidente } \\
\cline { 2 - 5 } & Lula II, Dilma I & FHC I, Lula I & FHC II & Collor, Dilma II \\
\hline $\begin{array}{l}\text { Rejeição da gestão presidencial } \\
\text { (ruim ou péssimo) }\end{array}$ & 0 & 0 & 0 & 1 \\
\hline Escândalos políticos & 1 & 1 & 1 & 1 \\
\hline Revoltas populares & 0 & 0 & 1 & 1 \\
\hline Média do PIB per capita & 0 & 0 & 0 & 1 \\
\hline Média da inflação acumulada & 0 & 1 & 0 & 1 \\
\hline Resultado & $\mathbf{0}$ & $\mathbf{0}$ & $\mathbf{0}$ & $\mathbf{1}$ \\
\hline
\end{tabular}

Legenda: Lula: Luiz Inácio Lula da Silva; Dilma: Dilma Rousseff; FHC: Fernando Henrique Cardoso; Collor: Fernando Collor de Mello. PIB: Produto Interno Bruto.

Fonte: os autores.

Podemos traduzir o contido no Quadro 5 da seguinte forma: para que o impeachment ocorra, deve existir um cenário econômico e social no qual (i) a rejeição da gestão presidencial (avaliação ruim ou péssima) seja igual ou superior a $50 \%$ por pelo menos 6 meses E (ii) haja escândalos políticos E (iii) tenham ocorrido revoltas populares contra o presidente que foram amplamente noticiadas $\mathrm{E}$ (iv) que tudo isso tenha se dado em um cenário de recessão econômica, ou seja, cuja média de crescimento do PIB ao longo dos anos da gestão foi negativa, assim como (v) a média da inflação acumulada durante a gestão tenha sido $>=8 \%$.

Em resumo, dentro dos valores de calibração propostos, todas as condições "não institucionais" estiveram presentes para que o resultado impeachment ocorresse. Vale destacar que dentro do conjunto de condições (i-iv) exposto acima, há algumas que são mais importantes do que outras para proporcionar o resultado (impeachment). Nesse sentido, a "rejeição da gestão presidencial" e o "crescimento negativo do PIB" são as condições necessárias de maior relevância, pois aparecem apenas nos casos em que o impeachment ocorreu 2 vezes (Collor e Dilma II). Nos termos de Goertz (2006), podem ser lidas como condições necessárias de máxima importância.

A impopularidade do presidente, entendida como a rejeição da gestão (ruim/péssimo) por um período prolongado de tempo - pelo menos 6 meses, tem levado a crises na coalizão e abalos na presidência (ABRANCHES, 2018, p. 350). No governo Collor, de acordo com o instituto Datafolha, a rejeição variou de $48 \%$ a $68 \%$ de março a setembro de 1992. Em Dilma II a rejeição ficou acima de $60 \%$ por 1 ano e 4 meses. As demais gestões conseguiram sempre manter um baixo índice de reprovação, ou contornaram o aumento da rejeição popular de forma bem-sucedida, como foi o caso em FHC II.

Quanto ao crescimento do PIB, no governo Collor a economia teve média de crescimento negativo de $-2,4 \%$, enquanto em Dilma II esse número chegou a $-4 \%$. Já a média da inflação ficou igual ou acima de $8 \%$ no governo Collor (1443\%), FHC I (23\%), Lula I (8,8\%) e Dilma II (8\%). A inflação, por si só, nos diz pouco e deve ser levada em consideração junto com outros indicadores econômicos.

Apenas na gestão Collor e Dilma II o País passou por um período de alta recessão econômica que não foi contornado em menos de 2 anos. O Gráfico 2 mostra como o governo de Fernando Collor de Mello conviveu com uma retração prolongada da economia de 1990 a 1992. O mesmo ocorreu com o governo de Dilma Rousseff: o crescimento negativo de $-0,35 \%$ em 2014 chegou a $-4 \%$ em 2015 e 2016. 
Gráfico 2 - Crescimento do Produto Interno Bruto (PIB) per capita (\%).

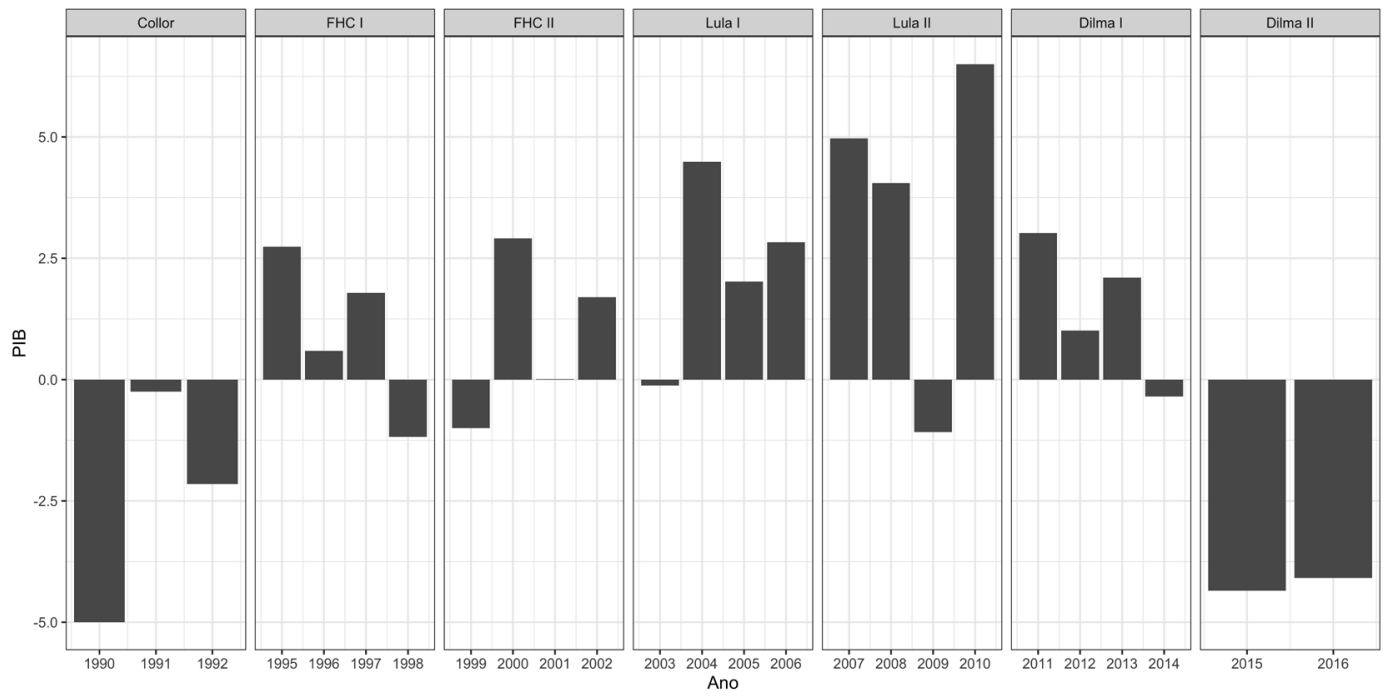

Legenda: Collor: Fernando Collor de Mello; FHC: Fernando Henrique Cardoso; Lula: Luiz Inácio Lula da Silva; Dilma: Dilma Rousseff.

Fonte: os autores, a partir dos dados do Banco Mundial.

Por sua vez, a condição "escândalo político" é a menos importante, visto que está presente em todos os governos. Pode-se dizer, portanto, que escândalos políticos amplamente noticiados pela mídia fazem parte do cotidiano da democracia brasileira e apesar de continuarem sendo causa necessária para que um impeachment ocorra, sua presença em todos os casos sinaliza para uma importância menor em relação às demais condições.

Já a condição "revoltas populares" apareceu como a terceira condição mais importante. A insatisfação com o governo quando expressada publicamente em grandes movimentos de rua é crucial para o sucesso ou fracasso da remoção presidencial. Foi assim no movimento dos "Caras Pintadas" em 1992 e também nos atos pro-impeachment de Dilma em 2015 e 2016. Quando olhamos para a "Marcha dos 100 mil" no governo FHC II, ocorrida em agosto de 1999, podemos dizer que essa condição esteve presente, mas o contexto era distinto do de Collor e Dilma II. A alta rejeição da gestão não se manteve estável e a economia, apesar do crescimento negativo, voltou a apresentar melhoras a partir dos anos 2000.

Partindo do raciocínio acima, podemos elencar as condições do Quadro 5 por ordem de importância da seguinte forma: rejeição da gestão presidencial maior que $50 \%$ por pelo menos 6 meses e média do PIB per capita (negativo) $>$ revoltas populares $>$ média da inflação acumulada (acima de $8 \%$ ) > escândalos políticos.

Essa é a vantagem do estudo aqui proposto. Ao compararmos os casos em que o impeachment ocorreu lado a lado com os casos em que ele não ocorreu, conseguimos avaliar a importância relativa de cada condição responsável por um impeachment bem-sucedido. Nesse sentido, a Teoria dos Conjuntos nos diz que o mau desempenho econômico e a baixa popularidade prolongada do presidente são as condições "não institucionais" mais importantes para que a remoção presidencial ocorra no Brasil.

Por fim, as condições "não institucionais" e "institucionais", ao serem mapeadas a partir do QCA, formam aquilo que a literatura denomina de “conjunto de condições necessárias mínimas" para que o resultado (impeachment) ocorra. Ou seja, o nosso Y (impeachment) ocorre sempre que W (configuração de condições) está presente (BLATTER; HAVERLAND, 2012, p. 93).

Nesse sentido, a partir da análise apresentada nesta seção, a remoção presidencial sempre 
ocorreu no Brasil quando a configuração de condições W1 - conjunto de condições necessárias "institucionais" - e W2 - conjunto de condições necessárias "não institucionais" - estiveram presentes. Vale destacar que $\mathrm{W} 1 * \mathrm{~W} 2$ levaram a $\mathrm{Y}$, mas a existência de outras configurações (W), ainda não identificadas, podem igualmente levar o presidente à destituição de seu cargo.

\section{Considerações finais}

Neste artigo buscamos identificar o conjunto lógico de condições necessárias e suficientes para a ocorrência de um impeachment bem-sucedido no Brasil. Tendo em vista o debate teórico, metodológico e os resultados obtidos com a análise das condições, destacamos aqui os três principais pontos de contribuição do artigo.

Em primeiro lugar, o presente estudo nos permitiu sistematizar as condições mínimas e necessárias para que um impeachment ocorra no Brasil. Apesar de a literatura indicar com frequência as condições e os fatores que atuam nos processos de instabilidade e remoção presidencial, análises qualitativas que investigam de modo comparativo casos de sucesso e fracasso ainda não são predominantes na área.

Em segundo lugar, assinalamos o estabelecimento da importância relativa de cada condição como uma contribuição desta pesquisa para o debate da remoção presidencial. Conforme demonstramos, a partir da observação da frequência pela qual as condições apareceram nas "tabelas verdade", foi possível inferir que o partido e a fidelidade partidária do presidente da Câmara dos Deputados é a condição institucional mais importante dentre as demais. Considerando a "tabela verdade" de condições não institucionais, observamos que a elevada rejeição popular (superior a $50 \%$ por pelo menos 6 meses) em relação ao governo do presidente e o mau desempenho econômico são as condições mais importantes do grupo. Por fim, vale destacar que a atribuição destes níveis de importância só foi possível graças à aplicação de uma estratégia metodológica ainda pouco utilizada dentro da Ciência Política brasileira. Nesse sentido, esperamos que o artigo possa integrar um corpo crescente de contribuições que adotem essa lente de observação do universo político.

\section{Referências}

ABRANCHES, S. Presidencialismo de coalizão: raízes e evolução do modelo político brasileiro. São Paulo: Companhia das Letras, 2018.

ALESSI, G. Com Collor e Dilma, a debandada de apoio na reta final do processo é igual. El País, São Paulo, 15 abr. 2016, Disponível em: https://bit. ly/2WxWNPG. Acessado em 01 set. 2019.

ALONSO, A. A política das ruas: protestos em São Paulo de Dilma a Temer. Novos Estudos CEBRAP, São Paulo, p. 49-58, 2017. Número especial.

ARAÚJO, C. M.; COSTA, S. F.; FITTIPALDI, Í. Boa noite, e boa sorte: determinantes da demissão de ministros envolvidos em escândalos de corrupção no primeiro governo Dilma Rousseff. Opinião pública, Campinas, v. 22, n. 1, p. 93-117, 2016. Doi: https://doi.org/10.1590/1807-0191201622193

ATO sem incidente grave tem policiamento recorde. Folha de S.Paulo, São Paulo, 27 ago. 1999b. Disponível em: https://bit.ly/2Y6xioS. Acesso em: 01 set. 2019.

AZEVEDO, F. Corrupção, mídia e escândalos midiáticos no Brasil. Em Debate, Belo Horizonte, v. 2, n. 3, p. 14-19, mar. 2010.

BERTHOLINI, F.; PEREIRA, C. Pagando o preço de governar: custos de gerência de coalizão no presidencialismo brasileiro. Revista de Administração Pública, Rio de Janeiro, v. 51, n. 4, p. 528550, 2017. Doi: https://doi.org/10.1590/00347612154969

BLATTER, J.; HAVERLAND, M. Design case studies: explanatory approaches in small-N research. London: Palgrave Macmillan, 2012.

CÂMARA DOS DEPUTADOS. Dados abertos $d a$ Câmara dos Deputados. Disponível em: https://bit. 1y/3zWT9wc . Acesso em: 4 set. 2019. 
CEBRAP. Banco de dados legislativos do Centro Brasileiro de Análise e Planejamento. São Paulo: Cebrap, 2019.

CHAIA, V.; TEIXEIRA, M. A. Democracia e escândalos políticos. São Paulo em Perspectiva, São Paulo, v. 15, n. 4, p. 62-75, 2001.

ECONOMIST comenta a marcha. Folha de S.Paulo, São Paulo, 28 ago. 1999c. Disponível em: https:// bit.ly/3F7Np6E. Acesso em: 01 set. 2019.

FIGUEIREDO, A.; LIMONGI, F. Bases institucionais do presidencialismo de coalizão. Lua Nova, São Paulo, v. 44, p. 81-106, 1998. Doi: https://doi. org/10.1590/S0102-64451998000200005

FIGUEIREDO, A.; LIMONGI, F. Instituições políticas e governabilidade. desempenho do governo e apoio legislativo na democracia brasileira. In: MELO, C. R.; SAEZ, M. A. A democracia brasileira: balanço e perspectivas para o século 21. Belo Horizonte: Editora UFMG, 2007. p. 147-198.

FREITAS, A. M. O presidencialismo de coalizão. 2013. 168 f. Tese (Doutorado em Ciência Política) Universidade de São Paulo, São Paulo, 2013.

GALLAGHER, M.; MITCHELL, P. The politics of electoral systems. Londres: Oxford University Press, 2019.

GOERTZ, G. Assessing the trivialness, relevance, and relative importance of necessary or sufficient conditions in social sciences. Studies in Comparative International Development, Saint Louis, v. 41, n. 2, p. 88-109, 2006.

IBARRA, R.; TRUPKIN, D. R. The relationship between inflation and growth: a panel smooth transition regression approach for developed and developing countries. Uruguay: Banco Central del Uruguay, 2011. (Working Paper Series; v. 6)

JONGRIM, H.; KOSE, M. A.; OHNSORGE, F. Inflation in emerging and developing economies: evolution, drivers, and policies. Washington: World Bank Publications, 2019.

KIM, Y. H. Impeachment and presidential politics in new democracies. Democratization, Oxford, v. 21, n. 3, p. 519-553, 2014.
KINZO, M. D. Partidos, eleições e democracia no Brasil pós-1985. Revista Brasileira de Ciências Sociais, São Paulo, v. 19, n. 54, p. 23-40, 2004. Doi: https://doi.org/10.1590/S0102-69092004000 100002

LAAKSO, M.; TAAGEPERA, R. "Effective" number of parties: a measure with application to west europe. Comparative Political Studies, Beverly Hills, v. 12, n. 1, p. 3-27, 1979. Doi: https://doi.org/10.1177\%2F001041407901200101

LAMOUNIER, B. Estrutura institucional e governabilidade na década de 90. In: VELLOSO, J. P. R. (ed.). O Brasil e as reformas politicas. Rio de Janeiro: José Olympio, 1992. p. 23-47.

LINZ, J. J. The perils of presidentialism. Journal of Democracy, Harvard, v. 1, n. 1, p. 51-69, 1990.

LLANOS, M.; MARSTEINTREDET, L. Presidential breakdowns in Latin America: causes and outcomes of executive instability in developing democracies. Nova York: Palgrave Macmillan, 2010.

MADUEÑO, D.; GONDIM, A.; ZORZAN, P. FHC enfrenta maior ato contra o seu governo hoje. Folha de S.Paulo, São Paulo, 26 ago. 1999a. Disponível em: https://bit.ly/3miKRKi. Acesso em: 01 set. 2019.

MANIFESTANTES fazem o maior protesto nacional contra o governo Dilma. Portal G1 Notícias, São Paulo, 13 mar. 2016. Disponível em: https:// glo.bo/3ipeQPv. Acesso em: 01 set. 2019.

MISCHE, A. Partisan publics: communication and contention across Brazilian youth activist networks. Princeton: Princeton University Press, 2008.

PEREIRA, C. Medindo a governabilidade no Brasil: o presidencialismo de coalizão nos governos FHC, Lula e Dilma. 2017. 88 f. Dissertação (Mestrado em Ciência Política) - Universidade de Brasília, Brasília, 2017.

PÉREZ-LIÑÁN, A. A two-level theory of presidential instability. Latin American Politics and Society, Cambridge, v. 56, n. 1, p. 34-54, 2014.

PÉREZ-LIÑÁN, A. Presidential impeachment and the new political instability in Latin America. Nova York: Cambridge University Press, 2007. 
PRADO, A. Além de Collor e Dilma, Sarney, Itamar, FH e Lula sofreram pedidos de impeachment. $O$ Globo, São Paulo, 5 maio 2016. Disponível em: https://glo.bo/3a21owG. Acesso em: 01 set. 2019.

RAGIN, C. The comparative method: moving beyond qualitative and quantitative strategies. Oakland: University of California Press, 1987.

SALLUM JR., B. Crise política e impeachment. Novos Estudos CEBRAP, São Paulo, v. 35, n. 2, p. 183-203, 2016.

SANTOS, F. Governos de coalizão no sistema presidencial: o caso do Brasil sob a Égide da Constituição de 1988. In: AVRITZER, L.; ANASTASIA, F. (ed.). Reforma politica no Brasil. Belo Horizonte: Editora UFMG, 2006. p. 223-236.

SCHNEIDER, C.; WAGEMANN, C. Set-theoretic methods for the social sciences: a guide to qualitative comparative analysis. Nova York: Cambridge University Press, 2012. 